\title{
Canadian healthcare readiness for public health emergencies
}

\author{
Cory Lefebvre, Adam Beswick, Lauren Crosby, Eric Mitchell \\ Faculty Reviewer: Ava John-Baptiste, PhD (Department of Epidemiology \& Biostatistics)
}

\section{ABSTRACT}

Following the 2003 SARS (Severe Acute Respiratory Syndrome) outbreak in Toronto, there remains a concern that Canada's healthcare systems are inadequately equipped to respond to a future public health emergency. Public health emergencies, defined as an emergency need for health care services to respond to a disaster, significant or catastrophic event, are economically costly. Effective prevention and responses to future emergencies would prevent economic costs like those from the 2003 SARS outbreak. An analysis from Hawryluck et al. of the SARS response identified major gaps: incomplete infection control, lack of system-wide communications, and no system-wide coordination leading to isolated, inefficient responses. More than a decade later, improvements have been made but there are areas in the infection control protocol that still require changes. More training is required for Emergency Medical Services (EMS) personnel to effectively handle emergency scenes and to improve multiple agency coordination. Local hospitals need to improve their surge capacity, administrative emergency preparedness infrastructure, and personnel training. The creation of the Public Health Agency of Canada (PHAC) in 2004 responded to concerns about the capacity of Canada's healthcare system to respond effectively to public health threats. At the provincial level, the Emergency Management Branch (EMB) works effectively similar to and in coordination with PHAC. The needs for improvement should question if Canada will be able to handle the next public health emergency that rolls through its door.

\section{INTRODUCTION}

In light of the recent outbreak of Ebola in West Africa, the aftermath of Hurricane Matthew, or the Louisiana floods that occurred during the past summer, it's not unreasonable to ask if the provincial and territorial healthcare systems and Canadian economy are ready to handle similar public health emergencies. The American National Disaster Medical System Federal Partners Memorandum of Agreement of 2005 defines public health emergencies as an emergency need for health care services to respond to a disaster, significant outbreak of an infectious disease, bioterrorist attack, or other significant or catastrophic event. ${ }^{1}$ We don't have to go far to study Canada's response in an emergency setting.

On February 23rd, 2003, the first case of SARS (Severe Acute Respiratory Syndrome), although undiagnosed at the time, presented in a Toronto patient that had recently traveled from Hong Kong. The disease spread in the Toronto region until June 2003, at which time the World Health Organization (WHO) removed Toronto from its list of infected areas. By the end of the outbreak, a total of 251 cases and 43 deaths were reported in Canada - the largest outbreak outside of Asia - while the majority of cases were in China, Hong Kong, Taiwan, and Singapore (7666 cases total, 718 deaths). The analysis of the outbreak's impact on the Canadian economy shows that it was partially or wholly responsible for a projected $1 \%$ loss in GDP and US $\$ 5.2$ billion net outflow of capital for imports/exports, not to mention the healthcare costs associated in dealing with the outbreak. $^{2}$

The response to the outbreak was far from perfect. Nearly a year following the outbreak, Hawryluck et al. studied the system's response to the virus' spread and identified several gaps in the system's efforts. ${ }^{3}$ The lack of infection control and the uncertainty of the level of safety precautions required stalled the response. There was also the need for system level control to avoid silo thinking, isolated responses, and to overcome issues with surge capacity and resource management. They identified a lack of a system-wide communications strategy to prevent the dissemination of misinformation and rumours, which caused distrust and anxiety among front-line workers, families, patients and the public. The article will focus on the healthcare system's capacity to respond to disaster and outbreak situations that require rapid and efficient action.

\section{FIRST-RESPONDER PREPAREDNESS}

In times of crisis, EMS (Emergency Medical Services) personnel are one of the first agencies to respond and require the proper training to handle MCI (mass casualty incidents), which can involve any situation from plane crashes to a CBRN (Chemical, Biological, Radiological or Nuclear) event. In a survey of EMS personnel in Ontario and British Columbia, there was an apparent lack of CBRN (Chemical, Biological, Radiological or Nuclear) event preparedness training. Around $60 \%$ of respondents received practical or theoretical training and, from these respondents only $61 \%$ received 'handson' training. A majority of respondents were trained in identifying a contaminated scene but only roughly $30 \%$ were trained in detecting radiation. Less than half of respondents were trained in identifying and treating symptoms of nerve agents, blistering agents, and asphyxiants. ${ }^{4}$ When surveyed about preparedness for MCI, 89\% of respondents have never received training for events involving tactical violence and $36 \%$ have never engaged in multiagency field exercises. ${ }^{5}$ The lack of training puts the safety and health of EMS personnel at risk, which may lead to anxiety and hesitation in firstline workers, and, ultimately, jeopardizes the effectiveness of the response. EMS are not the only first responders to a crisis scene and lack of training with other agencies decreases the cohesiveness, 
coordination, and effectiveness of the response efforts.

\section{LOCAL HOSPITAL PREPAREDNESS}

After the first-responder's response at the scene, the local hospital then needs to be ready to accommodate the influx of new patients. At the resource level, an assessment of Canadian hospitals' ICU (Intensive Care Unit) capacity revealed a variety of ICU resources geographically that would lead to a difference in the ability to care for an influx of new patients. ${ }^{6}$ When surveyed, $59 \%$ of trauma directors of Canadian trauma centres were not certain that their respective institutions had the capacity to sustain operations for at least 72 hours during a MCI. ${ }^{7}$ That being said, Critical Care Ontario - the managing body for critical care services in Ontario who collaborate with hospital administrators, healthcare providers, and MOHLTC - has a Surge Capacity Management Plan for situations where critical care demand exceeds available resources at local hospitals. ${ }^{8}$ Availability of resources at hospitals remains an issue for the whole system, and not just in the case of disasters and mass casualty incidents. In the context of a cash-strapped public healthcare system, influx of capital may not always be a viable answer to solving the resource drought. Developing resource management plans and being able to free up resources in cases of emergencies and disasters similar to what has been planned by the Critical Care Ontario plan are required for the future.

When it comes to appropriate resource management, a competent and intact administrative infrastructure is needed in times of crisis. In a study of Canadian trauma centres, more than $83 \%$ of respondents had committees for mass-casualty incidents but only half of the trauma directors sit on these committees. ${ }^{6}$ When examined for their preparation for CBRN events, there was a widespread lack of standard assessment and readiness knowledge when helping contaminated patients. ${ }^{9}$ Training for disaster situations at hospitals can also be improved. Of surveyed Canadian trauma centres, $43 \%$ of institutions had not run any drill in the previous 2 years ${ }^{7}$ and nurses across the country feel unprepared to respond to large disasters, with feeling the least prepared for CBRN events. ${ }^{10}$ At the local hospital level, tackling the issues of resource management, incomplete administrative infrastructure for crisis events, and training of personnel for various disasters is still needed to this day.

\section{GOVERNMENT SYSTEMS PREPAREDNESS}

In 2004, the Public Health Agency of Canada (PHAC) was created to focus on dealing with public health emergencies and infectious disease outbreaks in response to concerns about the capacity of Canada's healthcare system to respond effectively to public health threats. ${ }^{11}$ The agency's emergency preparedness and response was audited in 2010 to check if they were following their mandate. The audit identified the following deficiencies: "When it comes to planning and preparedness, the agency has a functional surveillance program but required to improve their sharing of information with partners and stakeholders." PHAC participated in numerous emergency exercises but failed to develop a long-term training and exercise plan or a large-scale public health/infectious disease exercise. It was noted that the agency is missing the human resource surge capacity for their EOC (Emergency Operations Centre), which acts as an effective command centre for coordination during a public health emergency. The audit also mentioned the lack of a robust method for identifying and learning lessons from previous response efforts. In the end, the audit concluded that PHAC was able to respond to emergencies but needed to address the identified deficiencies. ${ }^{12}$ A follow-up audit of the agency was performed in 2013 and found that all the recommendations from the 2010 report has been acted upon, with the majority of them having been fully implemented at the time of the report. ${ }^{13}$ The agency also manages the NESS (National Emergency Strategic Stockpile), a program that stockpiles health and social service supplies to be distributed to provinces and territories in emergencies, ${ }^{14}$ and HERTs (Health Emergency Response Teams), which assist provinces and territories with relief effects of medical and major health disasters. ${ }^{15}$

At the provincial level, the Emergency Management Branch (EMB) of the Ministry of Health and Long-Term Care (MOHLTC) coordinates the provincial's emergency response efforts focusing on human health, disease and epidemics, and maintaining health services during an emergency through the Ministry Emergency Response Plan. Many elements of the provincial plan mirror PHAC's emergency planning. The Ministry Emergency Operations Centre (MEOC) is the 24/7 command centre during emergencies with an extensive communication network. Emergency Medical Assistance Teams (EMATs) are mobile medical units deployable within 24 hours that support the local response efforts and enhance the local surge capacity. The MOHLTC also maintains stockpiles of antiviral medications, personal protective equipment, and mass immunizations supplies. EMB staff undergo training and participate regularly in exercises that range from tabletop exercises to mass immunization to mock deployments of EMATs. ${ }^{16}$ The planning and preparation for public health disasters at the provincial and federal levels has shown great improvement since the SARS outbreak, in part due to the creation of the PHAC and its emergency plan. Regular auditing of these agencies are required though to ensure that they maintain these standards of preparedness at a systemic level.

\section{CONCLUSION}

Some lessons have been learned since the SARS outbreak and been used to improve the system's capacity to respond. Looking specifically at the Ebola and Zika responses, there has been an increase in funding from the federal government for research, PHAC, and humanitarian efforts. ${ }^{17,18}$ Training for emergencies have continued with Ebola rapid response teams going through exercise simulations. To deal with infection control, the federal government has installed mandatory quarantine and staying of visa applications to individuals from Ebola affected regions, drawing strong criticism for the lack of evidence supporting the effectiveness of quarantine for Ebola. ${ }^{19}$

Overall, there are gaps that remain in our system's ability to respond to public health emergencies in general. More training and simulation exercises for EMS first responders and hospital staff are 
needed to mount an effective and efficient local response. Improving system-wide communications at the first-responder and local hospital levels is needed along with more cross-agency simulations. Local hospital surge capacity and resource management is another issue that can be resolved with improved emergency administrative infrastructure. The creation of PHAC and the MOHLTC's EMB to curate public health emergency response efforts on a systemic level should be able to overcome the challenge of siloed planning and isolated local responses noted in the SARS response. This need for improvement should question if Canada will be able to handle the next public health emergency that rolls through its door.

\section{REFERENCES}

1. National Disaster Medical System. Memorandum of Agreement among the Departments of Homeland Security, Health and Human Services, Veterans Affairs, and Defense. Washington DC: National Disaster Medical System; 2015. Available from: http://www.dtic.mil/doctrine/ doctrine/interagency/dhs_moa_diaster_med_system2005.pdf.

2. Keogh-Brown MR, Smith RD. The economic impact of SARS: How does the reality match the predictions? Health Policy. 2008 Oct;88(1):110-120.

3. Hawryluck L, Lapinsky SE, Stewart TE. Clinical review: SARS-lessons in disaster management. Crit Care. 2005 Aug;9(4):384-389.

4. Kollek D, Welsford M, Wanger K. Chemical, biological, radiological and nuclear preparedness training for emergency medical services provide. CJEM. 2008 Jul;11(4):337-42.

5. Kollek D, Welsford M, Wanger K. Canadian operational and emotional prehospital readiness for a tactical violence event. Prehosp Disaster Med. 2010 Apr;25(2):164-169.

6. Fowler RA, Abdelmalik P, Wood G, et al. Critical care capacity in Canada: results of a national cross-sectional study. Critical care. 2015;19(133).

7. Gomez D, Haas B, Ahmed N, Tien H, Nathens A. (2011) Disaster preparedness of Canadian trauma centres: the perspective of medical directors of trauma. Can J Surg. 2011 Feb;54(1):9-16.

8. Critical Care Services Ontario. Ontario's Critical Care Surge Capacity Management Plan. 2013. Available from: https://www.criticalcareontario.ca/EN/Toolbox/Surge\%20Capacity\%20Planning/Ontario\%20 Moderate\%20Surge\%20Response\%20Guide\%20(2013).pdf.

9. Kollek D, Cwinn AA. Hospital Emergency Readiness Overview Study. Prehospital and Disaster Medicine. 2011 Jun;26(3):159-65.

10. O'Sullivan TL, Dow D, Turner MC, et al. Disaster and emergency management: Canadian nurses' perceptions of preparedness on hospital front lines. Prehosp Disaster Med. 2008 Jun;23(3):s11-8.

11. Public Health Agency of Canada [Internet]. History; 2008 Apr 4 [Cited 2016 Nov 22]. Available from: http://www.phac-aspc.gc.ca/about_apropos/history-eng.php.

12. Audit Services Division - Public Health Agency of Canada. Audit Report: Emergency Preparedness and Response. 2010. Available from: http://www.phac-aspc.gc.ca/about_apropos/asd-dsv/ar-rv/2010/eprmiu-eng.php.

13. Portfolio Audit and Accountability Bureau - Public Health Agency of Canada. Follow-up Audit of Emergency Preparedness and Response. 2013. Available from: http://www.phac-aspc.gc.ca/about_apropos/asddsv/ar-rv/2013/assets/pdf/epr-mid-eng.pdf.

14. Public Health Agency of Canada [Internet]. National Emergency Strategic Stockpile; 2015 May 7 [cited 2016 Nov 22]; Available from: http:// www.phac-aspc.gc.ca/ep-mu/ness-eng.php.

15. Public Health Agency of Canada [Internet]. Bioterrorism and Emergency Preparedness; 2012 Jun 18 [cited 2016 Nov 22]; Available from: http://www.phac-aspc.gc.ca/ep-mu/bioem-eng.php.

16. Ministry of Health and Long-Term Care. Emergency Management 2013 Annual Report. 2014 Jan. Available from: http://www.health.gov. on.ca/en/pro/programs/emb/docs/compliance_2013.pdf.

17. Government of Canada [Internet]. Canada's response to Ebola; 2015 Dec 08 [cited 2016 Nov 22]. Available from: http://www.healthycanadians.gc.ca/diseases-conditions-maladies-affections/disease-maladie/ ebola/response-reponse/index-eng.php.

18. Federal government announces $\$ 5 \mathrm{M}$ to help Zika virus fight. CBC News [Internet]. 2016 May 11 [cited 2016 Nov 22]; Available from: http://www.cbc.ca/news/politics/funding-zika-virus-right-1.3577428.

19. Sharma M, Upshur R, Orbinski J. Canada's response to Ebola driven by fear, not evidence. The Globe and Mail [Internet]. 2014 Nov 13 [cited 2016 Nov 22]; Available from: http://www.theglobeandmail.com/ opinion/canadas-response-to-ebola-driven-by-fear-not-evidence/ article21570606/. 